\title{
Effect of pinealectomy on plasma melatonin, prolactin and progesterone concentrations during seasonal reproductive quiescence in the tammar, Macropus eugenii
}

\author{
S. J. McConnell* and L. A. Hinds $\dagger$ \\ Department of Behavioural Biology, Research School of Biological Sciences, Australian National \\ University, A.C.T. and $\dagger$ Division of Wildlife and Rangelands Research, CSIRO, P.O. Box 84, \\ Lyneham, A.C.T. 2602, Australia
}

\begin{abstract}
Summary. Non-lactating female tammars were pinealectomized $(\mathrm{N}=5)$ or shamoperated $(\mathrm{N}=6)$ in October, during the austral period of increasing daylength. After autopsy in February the completeness of pinealectomy was assessed by histological examination of the epithalamic region. Pinealectomy, but not the sham-operation, abolished the nocturnal rise in plasma melatonin but weekly plasma prolactin concentrations were similar in both groups from October to February. Plasma progesterone concentrations remained low $(<160 \mathrm{pg} / \mathrm{ml})$ in both groups until after the summer solstice in December, when there was a $2-4$-fold increase $(>300 \mathrm{pg} / \mathrm{ml}$ ) by late January, indicating reactivation of the quiescent corpus luteum. The mean date of birth or oestrus for the pinealectomized tammars was January $11 \pm 4.8$ days (s.e.m.), and for the sham-operated tammars January $24 \pm 5 \cdot 1$ days. These results demonstrate that the pineal is not necessary for the maintenance of seasonal quiescence or to induce reactivation of the corpus luteum at the start of the normal breeding season after the summer solstice.
\end{abstract}

\section{Introduction}

Although many studies have demonstrated a role of the pineal gland and its hormone melatonin in seasonal reproduction of eutherian mammals (Reiter, 1974; Kennaway, 1984), there is relatively little evidence for a similar role in marsupials. To date this has only been examined in one marsupial, the tammar.

The tammar is native to southern Australia and photoperiod appears to regulate the annual breeding cycle: $80 \%$ of the females give birth in the summer months of January and February after reactivation of a quiescent corpus luteum (CL) and blastocyst (Renfree \& Tyndale-Biscoe, 1973). This may be a response to decreasing daylength after the summer solstice in December, because a decrease in daylength from $15 \mathrm{~h}$ light:9 $\mathrm{h}$ dark (15L:9D) to $12 \mathrm{~L}: 12 \mathrm{D}$ at the vernal equinox induced reactivation in non-lactating animals within 2-9 days (Sadleir \& Tyndale-Biscoe, 1977). Oestrus and ovulation occur within 2 days of birth (Sutherland, Evans \& Tyndale-Biscoe, 1980) and the newly formed $\mathrm{CL}$ and blastocyst enter quiescence in response to sucking by the pouch young. Removal of the pouch young before the winter solstice in June reactivates the CL and blastocyst, and the females are therefore said to be in lactational quiescence during the period of decreasing daylength. After the winter solstice, however, removal or weaning of the pouch young is ineffective and this seasonal quiescence persists during the period of increasing daylength.

Both lactational and seasonal quiescence are due to suppression of luteal growth by the pituitary, because hypophysectomy at either time of year causes the CL to be reactivated (Hearn,

*Present address: Institut für Tierzucht und Tierverhalten, Mariensee 3057, Neustadt 1, Federal Republic of Germany. 
1973, 1974). Prolactin appears to be the hormone responsible, as daily prolactin injections after removal of the pouch young in lactational quiescence, or after hypophysectomy in seasonal quiescence, delayed reactivation for the duration of the treatment (Tyndale-Biscoe \& Hawkins, 1977) and plasma prolactin concentrations are elevated in seasonal quiescence (Tyndale-Biscoe \& Hinds, 1984). Prolactin may also be involved in the response of the tammar to photoperiod change. After a decrease from 15L:9D to 12L:12D plasma prolactin concentrations declined to basal levels within 14 days, and plasma progesterone concentrations increased, indicating a resumption of luteal activity (Hinds \& den Ottolander, 1983).

Renfree, Lincoln, Almeida \& Short (1981) reported that superior cervical ganglionectomy in March-May abolished the nocturnal rise in plasma melatonin and the subsequent seasonal quiescence, suggesting that the pineal was necessary for seasonal quiescence, possibly by suppressing the seasonal rise in prolactin secretion. When the pouch young of these ganglionectomized tammars were lost or removed in July-August, their corpora lutea and blastocysts reactivated, resulting in births $27-28$ days later. We have therefore investigated whether pinealectomy in October would also abolish the nocturnal melatonin rise, lead to depressed concentrations of prolactin and allow immediate reactivation of the $\mathrm{CL}$ and blastocyst to occur.

\section{Materials and Methods}

Animals. The tammars used in this study were obtained from breeding colonies maintained at the Division of Wildlife and Rangelands Research, CSIRO Australia, and the Department of Behavioural Biology, Australian National University. Both colonies are derived from original stocks brought from Kangaroo Island, South Australia, in 1974 and 1980 respectively.

Experimental design. Non-lactating tammars were subjected to the pinealectomy $(\mathrm{N}=6)$ or sham-pinealectomy $(\mathrm{N}=6)$ procedures described below, between 12 and 20 October 1981 . Three of the sham-operated tammars died shortly after surgery (see below) so another three were included. After a 3-day recovery period in a post-operative pen with natural lighting, all the tammars were returned to an outside yard with sexually mature males. Every 2-3 days their pouches were examined for birth, and the urogenital sinus for a copulatory plug, indicative of oestrus.

To monitor the pre- and post-operative profiles of plasma melatonin and prolactin, blood samples over a $24-\mathrm{h}$ period were taken every $4 \mathrm{~h}$ from a lateral tail vein on 22-23 September and again on 18-19 November.

Blood samples for plasma progesterone and prolactin measurements were also taken at weekly intervals between 09:00 and 11:00 h until detection of birth or oestrus, and at autopsy in February 1982.

Assays. Melatonin was measured by the radioimmunoassay of Kennaway, Gilmore \& Seamark (1982) using antiserum G280 kindly supplied by Dr D. J. Kennaway, Department of Obstetrics and Gynaecology, The University of Adelaide. The radioimmunoassay has been validated for the tammar by McConnell \& Tyndale-Biscoe (1985). Sensitivity of the assay was $23.5 \pm 10.6 \mathrm{pg} / \mathrm{tube}$, and the intra- and inter-assay coefficients of variation were $10 \%$ and $17 \%$ respectively. Progesterone concentrations were determined by the radioimmunoassay validated for the tammar by Sernia, Hinds \& Tyndale-Biscoe (1980) using antiserum S230 kindly donated by Dr R. I. Cox, Division of Animal Production, CSIRO. Sensitivity of the assay was $25 \mathrm{pg} / \mathrm{ml}$ and the intra- and inter-assay coefficients of variation were $9 \%$ and $13 \%$ respectively. Prolactin was measured by the radioimmunoassay of McNeilly \& Friesen (1978) validated for the tammar by Hinds \& TyndaleBiscoe (1982). Sensitivity of the assay was $3 \mathrm{ng} / \mathrm{ml}$ and the intra- and inter-assay coefficients of variation were $8 \%$ and $12 \%$ respectively. 


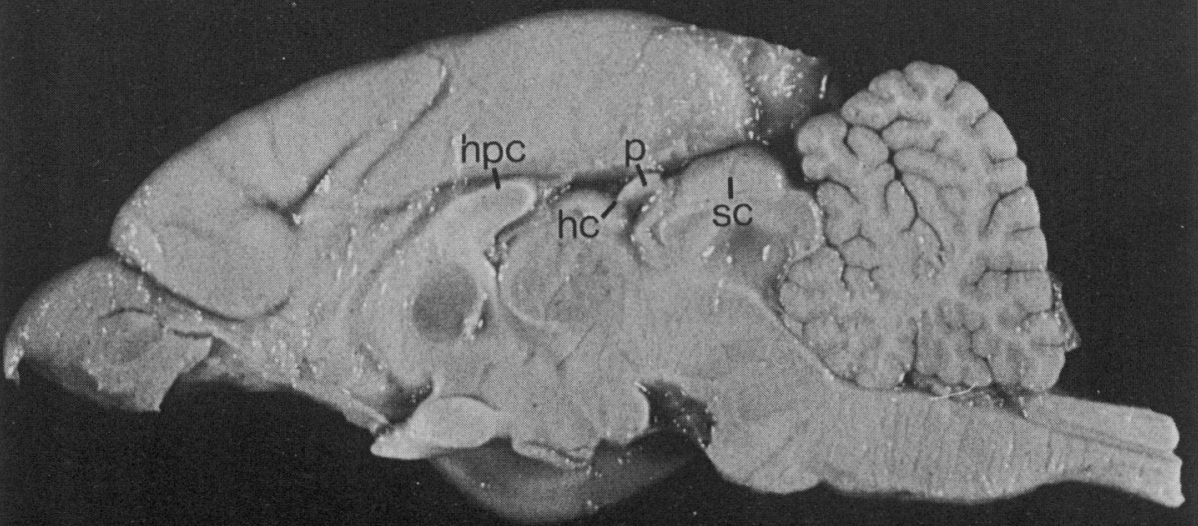

2

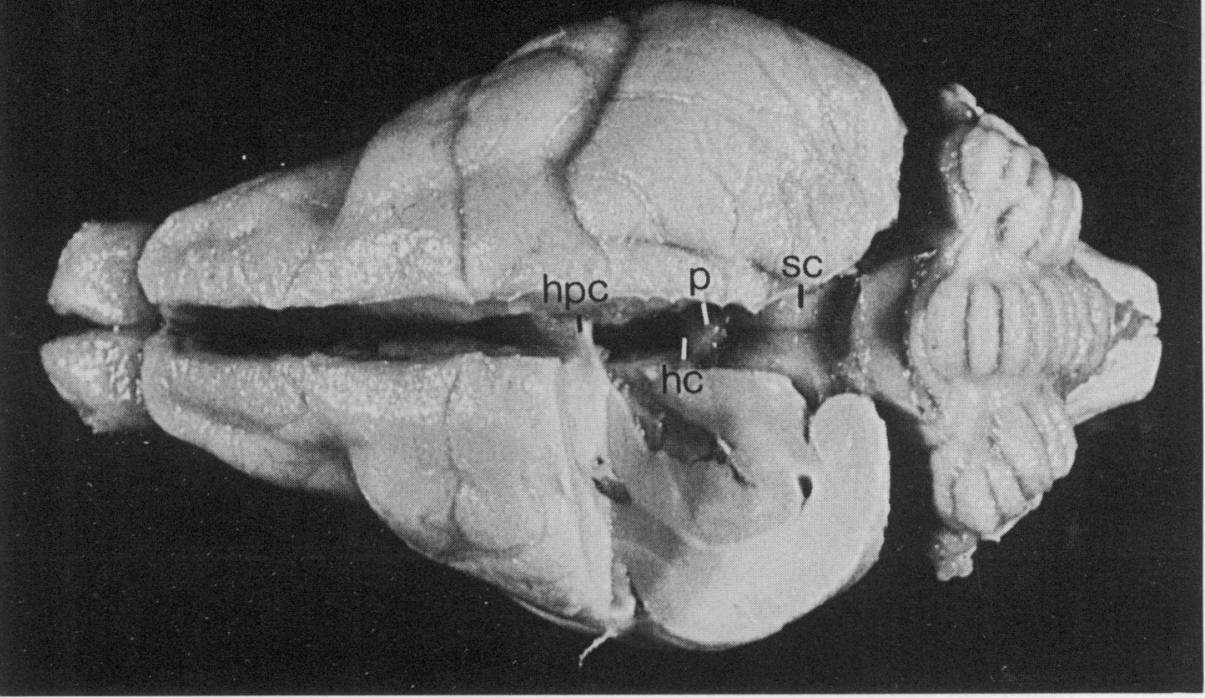

Formaldehyde-fixed tammar brains cut in the mid-sagittal plane (Fig. 1) and shown from the dorsal aspect with the left occipital cortex removed (Fig. 2) to show the position of the pineal gland relative to other neural structures. hpc. hippocampal commissure: he, habenular commissure: sc. superior colliculus; p. pineal. 
Pinealectomy procedure. The pineal gland of the tammar is situated between the anterior aspect of the superior colliculi, connected to the habenular commissure anteriorly and the posterior commissure posteriorly (Plate 1). The lack of a corpus callosum in the tammar allowed the pineal to be approached directly from the top of the skull without division of nerve tracts. Anaesthesia was induced and maintained by an intravenous infusion of thiamylal sodium (Surital: Parke-Davis, Sydney, Australia), followed by $0.12 \mathrm{mg}$ atropine sulphate (Lancet Pharm., Sydney, Australia). The scalp was shaved and scrubbed with Cetavlon (I.C.I., Melbourne, Australia) and the head secured with a mouth bar and masking tape to a platform mounted on a ball joint. This allowed fine adjustments of orientation during surgery, which was performed under a binocular surgical microscope (Carl Zeiss Jena, Model 310). A midline scalp incision was made extending from the coronal suture to the occipital protuberance. The left temporalis muscle was freed and deflected. A $14 \times 7 \mathrm{~mm}$ plate was cut with a round dental burr through the parietal bone to the dura mater, $2 \mathrm{~mm}$ caudal to the coronal suture and $1 \mathrm{~mm}$ lateral to the sagittal suture. The dura mater was split leaving a 2-3-mm margin at the rostral, caudal and ipsilateral edges to support the replaced bone plate. The cerebral hemisphere was displaced with a small spatula to expose the falx cerebri down into the epithalamic region. An aspirator was used to remove cerebrospinal fluid and to displace the choroid plexus, and the hippocampal and habenular commissures were identified (Plate 1). The pineal gland was readily recognized by its reddish-grey colour, and was found connected, and lying caudal, to the habenular commissure. A mass of vascular tissue often obscured the pineal but this could be displaced with the aspirator. Due to the attachment of the pineal to the habenular commissure, removal of all pineal tissue without damage to the commissure was considered unfeasible. For this reason the habenular commissure was cut on both sides and removed together with the pineal by aspiration through a blunt 14-gauge needle. Any bleeding was controlled with a gelatin sponge (Gelfoam: Upjohn, MI, U.S.A.) and when haemostasis was achieved, the resultant clot was gently removed. The epithalamic region was then checked for remnants of pineal tissue. The interhemispheric fissure was filled with sterile saline $(0.9 \%(\mathrm{w} / \mathrm{v}) \mathrm{NaCl})$ at $37^{\circ} \mathrm{C}$, allowing the deflected hemisphere to return to its normal position, and the dural flap was replaced and sutured at the margins using polyglycolic acid sutures (Dexon: Davis \& Geck, Sydney, Australia).

The bone plate was replaced and manipulated in situ to check for bleeding. Antibiotic powder (Tricin: V. R. Laboratories, Sydney, Australia) was applied to the wound which was closed with wound clips. For the sham procedure the habenular commissure was cut but the pineal palpated only. The decision to proceed to pinealectomy or not was determined randomly after sectioning the habenular commissure. As a prophylactic measure against infection $1 \mathrm{ml}$ antibiotic (Aquacaine: C.S.L., Melbourne, Australia) was injected i.m. after surgery.

To validate the surgery the tammars were killed by barbiturate overdose on 25-26 February 1982 and the head region was fixed with a ventricular infusion of $10 \%$ formal saline. The brain was removed and the epithalamic region isolated and embedded in hen's egg yolk. Serial frozen sections $(40 \mu \mathrm{m})$ were taken for staining with cresyl violet. The sections were mounted and examined independently by both of us for evaluation of the completeness of pinealectomy.

\section{Results}

\section{General effects of surgery}

Two tammars subjected to the sham-pinealectomy procedure died within $48 \mathrm{~h}$ of surgery. At autopsy intra-cerebral haemorrhage was found in one, and this was suspected to be the cause of death. This was not obvious in the other, and the cause of death was unknown. A third sham-operated tammar rapidly became weak and emaciated and so was killed 2 days after surgery. No adverse effects of surgery were obvious in the remaining 9 tammars or in the 3 replacement tammars. 


\section{Histology}

Examination of the sections of the epithalamic region revealed that the pineal had been completely removed in all but one of the 6 tammars subjected to the pinealectomy procedure. This animal was excluded from all post-operative analyses. In the 6 surviving sham-operated tammars the pineal was present.

\section{Melatonin profiles}

Before surgery plasma melatonin concentrations were elevated during the night in each of the tammars (Text-fig. 1a), and the mean concentration during the dark phase was significantly higher than that of the light phase $(P<0.05$, Student's $t$ test). Pinealectomy abolished this nocturnal rise in all tammars (Text-fig. 1b) and melatonin was undetectable at all time points in 3 of these. In the remaining 2 animals, daily mean \pm s.e.m. concentrations were $44.7 \pm 4.6$ and $44.0 \pm 3.5 \mathrm{pg} / \mathrm{ml}$. A significant nocturnal elevation persisted in the sham-operated tammars (Text-fig. 1b).

\section{Prolactin profiles}

The plasma prolactin concentrations determined at weekly intervals remained at the same level in the pinealectomized and sham-pinealectomized animals from October to February (Text-fig. 2), and there were no significant differences between the groups at any time $(P>0.05$, Student's $t$ test for independent samples). However, an analysis of variance of the 24-h prolactin profiles (Text-fig. $3)$ indicated a significant difference between the treatments $(P<0 \cdot 05, F 6 \cdot 14$, d.f. 22). The prolactin

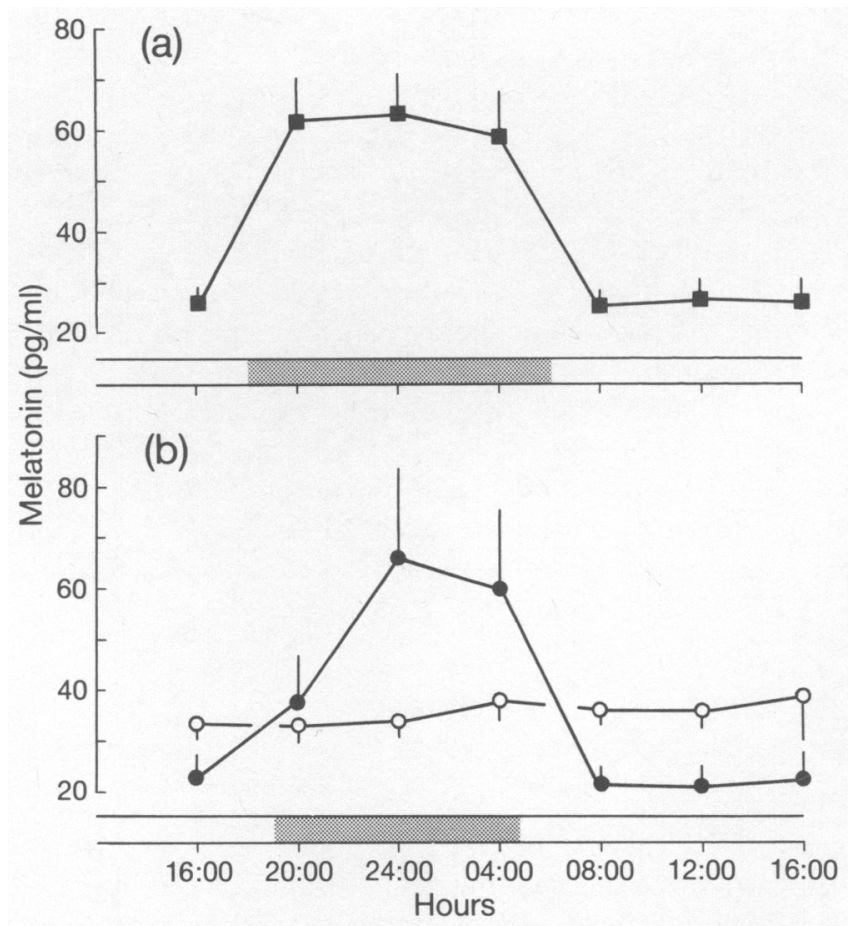

Text-fig. 1. The 24-h profiles of plasma melatonin measured in tammars (a) pre-operatively ( $\square$, $\mathrm{N}=12)$ and (b) after pinealectomy $(\mathrm{O}, \mathrm{N}=5)$ or sham-pinealectomy $(\mathbf{O}, \mathrm{N}=6)$ in October. Stippled bars indicate the dark phase of each photoperiod. Values are mean \pm s.e.m. 


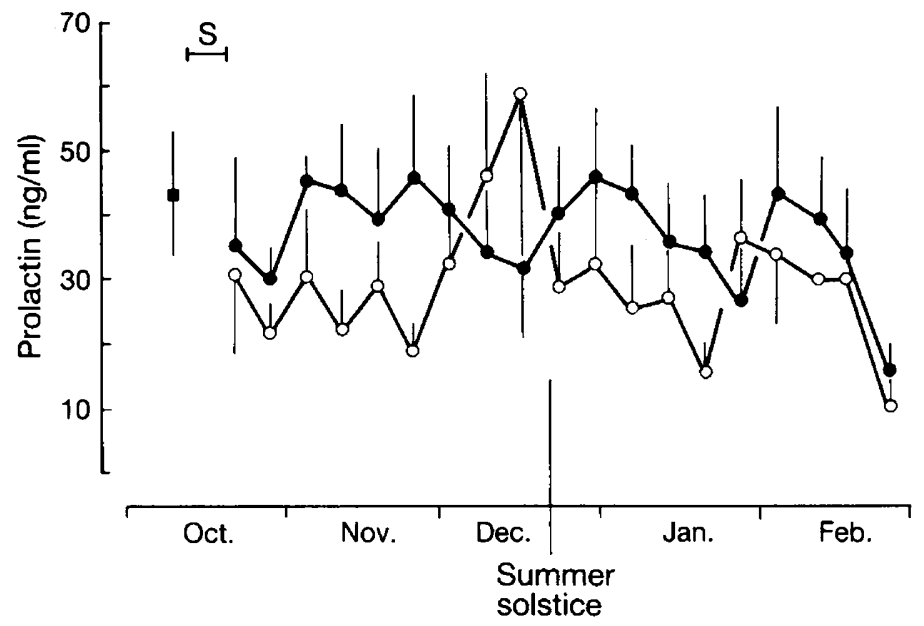

Text-fig. 2. Weekly plasma prolactin concentrations in tammars measured pre-operatively ( $\square$, $\mathrm{N}=12)$ and after pinealectomy $(O, N=5)$ or sham-pinealectomy $(0, N=6) . S=$ period of surgery for whole group. Values are mean \pm s.e.m.

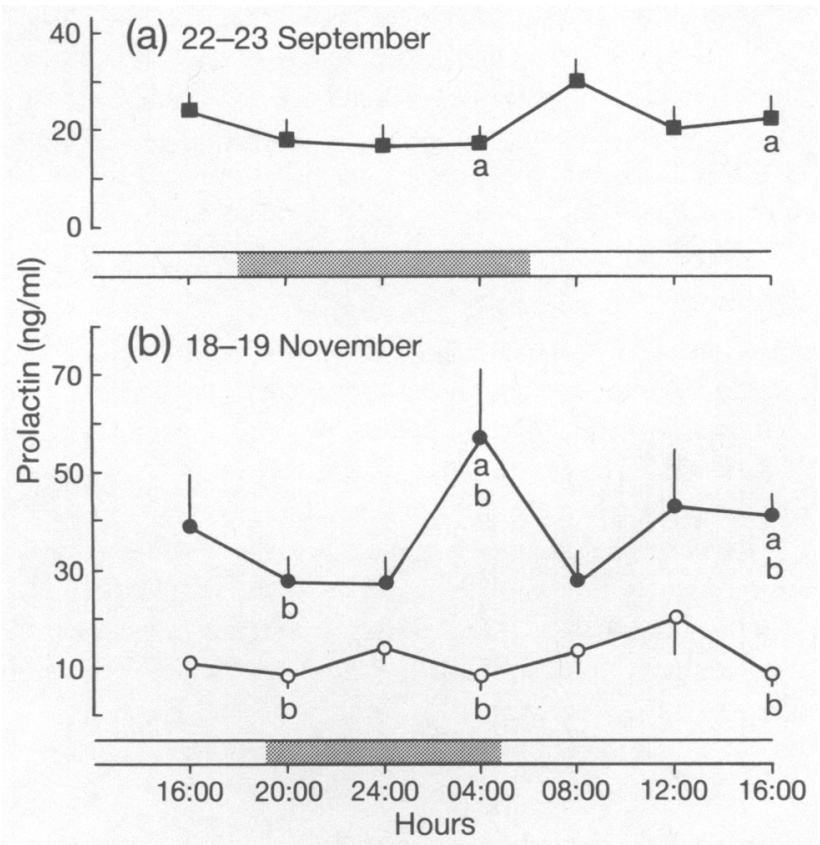

Text-fig. 3. The 24-h profile of plasma prolactin concentrations measured in tammars (a) pre-operatively $(\boldsymbol{U}, \mathbf{N}=12)$ and (b) after pinealectomy $(O, N=5)$ or sham-pinealectomy $(O$, $\mathrm{N}=6$ ) in October. Stippled bars indicate the dark phase of each photoperiod. Values given are the mean \pm s.e.m. At each time means with the same letters are significantly different $(P<0.02$, Student's $t$ test $)$.

levels of the sham-operated tammars, determined in November, were significantly higher than the preoperative concentrations in September at 04:00 and 16:00 h $(P<0.02)$, and than those of the pinealectomized tammars at 20:00, 04:00 and 16:00 h $(P<0.02$, Student's $t$ test for pairwise comparisons (c) where $\alpha=\alpha / c$; Harris, 1975, p. 13). No significant differences were found between the preoperative concentrations in September and those of the pinealectomy group in November. 


\section{Progesterone profiles}

In the pinealectomized and the sham-operated tammars plasma progesterone concentrations remained low $(<160 \mathrm{pg} / \mathrm{ml})$ until after the summer solstice (Text-fig. 4). By late January there was a 2-4-fold increase ( $>300 \mathrm{pg} / \mathrm{ml}$ ) indicating a resumption of luteal development. A decline to basal levels had occurred by early February. There were no significant differences between the groups at any time ( $P>0.05$, Student's $t$ test for independent samples). These profiles are similar to those reported previously for normal tammars after spontaneous reactivation at this time (Tyndale-Biscoe \& Hinds, 1984).

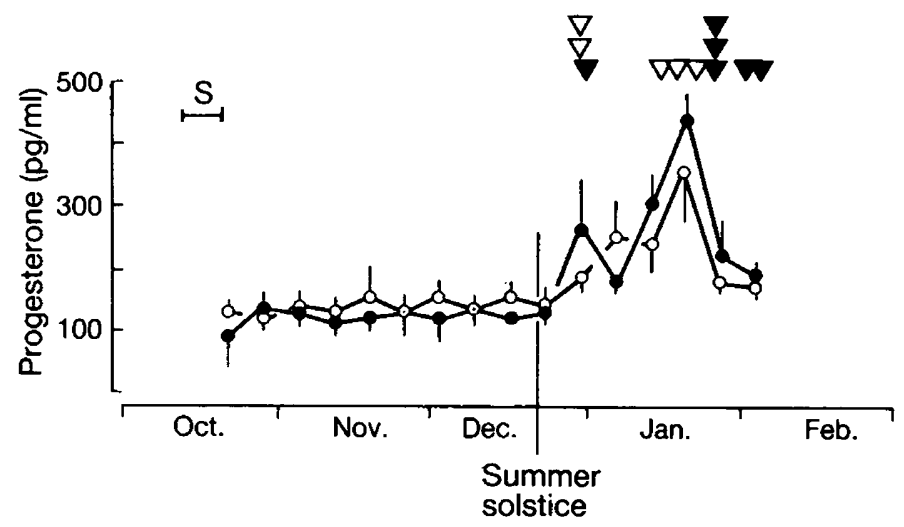

Text-fig. 4. Plasma progesterone concentrations in tammars that were pinealectomized $(O)$ or sham-operated $(\bullet)$ during seasonal quiescence. $S=$ period of surgery for whole group. The day of birth/oestrus in each pinealectomized $(\nabla)$ and sham-operated $\operatorname{tammar}(\boldsymbol{\nabla})$ is indicated.

\section{Birth or oestrus after surgery}

None of the tammars that were pinealectomized or sham-operated in October gave birth or displayed oestrus before the summer solstice, but all gave birth and/or came into oestrus from late December to early February (Text-fig. 4). The pinealectomized tammars gave birth $(\mathrm{N}=2)$ or displayed oestrus $(\mathrm{N}=3$ ) between 30 December and 22 January (Jan. $11 \pm 4.8$ days, mean \pm s.e.m.). The sham-operated tammars gave birth $(\mathrm{N}=1)$ or displayed oestrus $(\mathrm{N}=5)$ from 31 December to 4 February (Jan. $24 \pm 5 \cdot 1$ days). The mean \pm s.e.m. interval from pinealectomy to birth or oestrus ( $87.8 \pm 4.9$ days) was significantly less than the interval from sham-operation to birth or oestrus (103.8 \pm 2.3 days, $P<0.05$, Student's $t$ test for independent samples). However, the distribution of births recorded in this small group of animals is within the range observed in intact animals on Kangaroo Island, South Australia (Sadleir \& Tyndale-Biscoe, 1977) and in the captive colony at CSIRO Division of Wildlife \& Rangelands Research, Canberra.

\section{Discussion}

This study has shown that the nocturnal increase in plasma melatonin concentrations is of pineal origin in the tammar because it was abolished by pinealectomy. However, there may be another source of melatonin in the tammar, because basal plasma concentrations were still detected in two pinealectomized tammars during both the light and dark phases (Text-fig. 1b). Melatonin has also been measured by radioimmunoassay in the plasma of rats (Ozaki \& Lynch, 1976) and ewes (Kennaway, Frith, Phillipou, Matthews \& Seamark, 1977) after pinealectomy, while the presence of a 24-h rhythm in retinal melatonin content of pinealectomized rats (Yu, Pang \& Tang, 1981) suggests that other tissues may contribute to the plasma melatonin pool. The persistence of the nocturnal elevation of plasma melatonin in the sham-operated tammars demonstrates that the 
sham procedure did not interfere with the circadian pattern of melatonin synthesis so, in terms of this indole, the pineal remained functional.

Renfree et al. (1981) reported that, in tammars ganglionectomized between March and May, the loss or removal of their pouch young in July-August induced immediate reactivation of the corpus luteum, resulting in birth 27-28 days later. This effect was attributed to denervation of the pineal gland, as the nocturnal melatonin rise was abolished, and may have been due to suppression of the seasonal rise in prolactin secretion. In the present study, pinealectomy did not abolish seasonal quiescence: the plasma progesterone profiles showed that the corpora lutea of all the pinealectomized and sham-operated tammars remained quiescent until reactivation in late December-January, and birth/oestrus occurred at the start of the normal breeding season. These results demonstrate that removing the pineal did not affect the maintenance of seasonal quiescence after October or the subsequent reactivation of the corpus luteum and blastocyst at the start of the next breeding season. The weekly prolactin profile failed to reveal an effect of pinealectomy, although these samples were taken between 09:00 and 11:00 h, when the 24-h profile indicated that there were no significant differences (Text-fig. 3). However, since in a detailed study by Hinds \& Tyndale-Biscoe (1985) there was no consistent pattern of prolactin secretion in one non-lactating and 5 lactating tammars sampled hourly over $28 \mathrm{~h}$ and at 6 different times of year, the significance of the differences in the $24-\mathrm{h}$ prolactin profile for samples collected only at 4 -h intervals must be viewed with caution. This study has therefore been unable to demonstrate any direct relationship between plasma prolactin concentrations during seasonal quiescence and the role of the pineal in reproduction in the tammar.

The persistence of seasonality after pinealectomy or ganglionectomy has been described for a variety of mammals, including the ewe (Roche, Karsch, Foster, Takagi \& Dziuk, 1970), ferret (Herbert, Stacey \& Thorpe, 1978), mare (Sharp, Vernon \& Zavy, 1979; Grubaugh et al., 1982) and white-tailed deer (Snyder, Cowan, Hagan \& Schanbacher, 1983), and in the absence of pinealmediated information, environmental cues, social cues or endogenous factors may regulate seasonality. However, since the results of the ganglionectomy study by Renfree et al. (1981) suggested that the pineal alone initiates seasonal quiescence, the differences in the effects of ganglionectomy and pinealectomy in the tammar may be due to inherent differences in the two surgical procedures. Although the neuroendocrine sequelae of pinealectomy and ganglionectomy are reportedly different (see Cardinali, Vacas \& Gejman, 1981), other studies have demonstrated similarities in their effects on reproduction (Herbert, 1968, 1969; Reiter \& Hester, 1966). If the latter is also true for the tammar then, as with the differences in the response to bromocriptine at different times of year (Tyndale-Biscoe \& Hinds, 1984), the apparent differences between ganglionectomy and pinealectomy may indicate that the response to loss of pineal-mediated information differs in lactational and seasonal quiescence.

Previous studies suggest that the experience of increasing daylength may initiate seasonal quiescence. Tammars in which the blastocyst was reactivated by a decrease in daylength continued to cycle after their pouch young were removed when maintained on static daylength (Hinds \& den Ottolander, 1983), but others failed to do so when exposed to ambient increasing daylength (McConnell \& Tyndale-Biscoe, 1985). If this inhibition is pineal-mediated, then the tammars ganglionectomized in March-May (before the change to increasing daylength after the winter solstice in June) would not have detected this change, and so failed to show seasonal quiescence. Alternatively those pinealectomized in October had already been exposed to increasing daylength and so displayed seasonal quiescence. This therefore suggests that, after seasonal quiescence is initiated by the pineal, it is no longer required to maintain quiescence, or for reactivation of the corpus luteum at the start of the breeding season, and so other endogenous or exogenous factors must be capable of imposing seasonality. Further investigations are required to discriminate between these alternatives, by comparing the effects of pinealectomy with ganglionectomy at different times of the year and to determine the importance of endogenous factors or extra-pineal photosensitivity for the persistence of seasonality after pinealectomy. 
We thank Mr R. Geppert and Mr R. Leckie for assistance in handling the tammars, Dr D. J. Kennaway for the gift of anti-melatonin antiserum, and Dr C. H. Tyndale-Biscoe and Professor R. F. Mark for the provision of facilities and advice on the surgical procedures. S.J.McC. was supported by a Commonwealth Postgraduate Research Award.

\section{References}

Cardinali, D.P., Vacas, M.I. \& Gejman, P.V. (1981) The sympathetic superior cervical ganglia as peripheral neuroendocrine centres. J. Neural Transmission 52, $1-21$.

Grubaugh, W., Sharp, D.C., Berglund, L.A., McDowell, K.J., Kilmer, D.M., Peck, L.S. \& Seamans, K.W. (1982) Effect of pinealectomy in Pony mares. $J$. Reprod. Fert., Suppl. 32, 293-295.

Harris, R.J. (1975) A Primer of Multivariate Statistics. Academic Press, London.

Hearn, J.P. (1973) Pituitary inhibition of pregnancy. Nature, Lond. 241, 207-208.

Hearn, J.P. (1974) The pituitary gland and implantation in the tammar wallaby, Macropus eugenii. J. Reprod. Fert. 39, 235-241.

Herbert, J. (1968) Prevention by pinealectomy of light-accelerated oestrus in the ferret. $J$. Endocr. 41, 20-21.

Herbert, J. (1969) The pineal gland and light induced oestrus in ferrets. J. Endocr. 43, 625-636.

Herbert, J., Stacey, P.M. \& Thorpe, D.A. (1978) Recurrent breeding seasons in pinealectomized or optic-nerve-sectioned ferrets. J. Endocr. 78, 389-397.

Hinds, L.A. \& den Ottolander, R.C. (1983) Effect of changing photoperiod on peripheral plasma prolactin and progesterone concentrations in the tammar wallaby (Macropus eugenii). J. Reprod. Fert. 69, 631-639.

Hinds, L.A. \& Tyndale-Biscoe, C.H. (1982) Prolactin in the marsupial Macropus eugenii, during the estrous cycle, pregnancy and lactation. Biol. Reprod. 26, 391-398.

Hinds, L.A. \& Tyndale-Biscoe, C.H. (1985) Seasonal and circadian patterns of circulating prolactin during lactation and seasonal quiescence in the tammar, Macropus eugenii. J. Reprod. Fert. 74, 173-183.

Kennaway, D.J. (1984) Pineal function in Ungulates. Pineal Research Reviews 2, 113-140.

Kennaway, D.J., Frith, R.G., Phillipou, G., Matthews, C.D. \& Seamark, R.F. (1977) A specific radioimmunoassay for melatonin in biological tissue and fluids and its validation by gas chromatography-mass spectrometry. Endocrinology 101, 119-127.

Kennaway, D.J., Gilmore, T.A. \& Seamark, R.F. (1982) Effect of melatonin feeding on serum prolactin and gonadotropin levels and the onset of seasonal estrous cyclicity in sheep. Endocrinology 110, 1766-1772.

McConnell, S.J. \& Tyndale-Biscoe, C.H. (1985) Response in peripheral plasma melatonin to photoperiod change and the effects of exogenous melatonin on seasonal quiescence in the tammar, Macropus eugenii. J. Reprod. Fert. 73, 529-538.

McNeilly, A.S. \& Friesen, H.G. (1978) Heterologous radioimmunoassay for rabbit prolactin. Endocrinology 102, 1539-1547.

Ozaki, Y. \& Lynch, H.J. (1976) Presence of melatonin in plasma and urine of pinealectomized rats. Endocrinology 99, 641-644.
Reiter, R.J. (1974) Circannual reproductive rhythms in mammals related to photoperiod and pineal function: a review. Chronobiologia 1, 365-395.

Reiter, R.J. \& Hester, R.J. (1966) Interrelationships of the pineal gland, the superior cervical ganglia and the photoperiod in the regulation of the endocrine systems of hamsters. Endocrinology 79, 1168-1170.

Renfree, M.B. \& Tyndale-Biscoe, C.H. (1973) Intra-uterine development after diapause in the marsupial Macropus eugenii. Devl Biol. 32, 28-40.

Renfree, M.B., Lincoln, D.W., Almeida, O.F.X. \& Short, R.V. (1981) Abolition of seasonal embryonic diapause in a wallaby by pineal denervation. Nature, Lond. 293, 138-139.

Roche, J.F., Karsch, F.J., Foster, D.L., Takagi, S. \& Dziuk, P.J. (1970) Effect of pinealectomy on estrus, ovulation and luteinizing hormone in ewes. Biol. Reprod. 2, 251-254.

Sadleir, R.M.F.S. \& Tyndale-Biscoe, C.H. (1977) Photoperiod and the termination of embryonic diapause in the marsupial Macropus eugenii. Biol. Reprod. 16, 605-608.

Sernia, C., Hinds, L. \& Tyndale-Biscoe, C.H. (1980) Progesterone metabolism during embryonic diapause in the tammar wallaby, Macropus eugenii. J. Reprod. Fert. 60, 139-147.

Sharp, D.C., Vernon, M.W. \& Zavy, M.T. (1979) Alteration of seasonal reproductive patterns in mares following superior cervical ganglionectomy. J. Reprod. Fert., Suppl. 27, 87-93.

Snyder, D.L., Cowan, R.L., Hagan, D.R. \& Schanbacher, B.D. (1983) Effect of pinealectomy on seasonal changes in antler growth and concentrations of testosterone and prolactin in white-tailed deer. Biol. Reprod. 29, 63-71.

Sutherland, R.L., Evans, S.M. \& Tyndale-Biscoe, C.H. (1980) Macropodid marsupial luteinizing hormone: validation of assay procedures and changes in concentrations in plasma during the oestrous cycle in the female tammar wallaby (Macropus eugenii). $J$. Endocr. 86, 1-12.

Tyndale-Biscoe, C.H. \& Hawkins, J. (1977) The corpora lutea of marsupials: aspects of function and control. In Reproduction and Evolution, pp. 245-252. Eds J. H. Calaby \& C. H. Tyndale-Biscoe. Australian Academy of Science, Canberra.

Tyndale-Biscoe, C.H. \& Hinds, L.A. (1984) Seasonal patterns of circulating progesterone and prolactin in response to bromocriptine in the female tammar Macropus eugenii. Gen. comp. Endocr. 53, 58-68.

Yu, H.S., Pang, S.F. \& Tang, P.L. (1981) Increase in the level of retinal melatonin and persistence of its diurnal rhythm in rats after pinealectomy. J. Endocr. 91, 477.481 . 